\title{
Multiple authorship of scientific manuscripts
}

\author{
Martin Caon ${ }^{1}$
}

Published online: 22 December 2016

(C) Australasian College of Physical Scientists and Engineers in Medicine 2016

The authors of a manuscript determine who is listed as an author and in what order they are listed. However, the authorship list should be settled amongst the authors before submitting the manuscript to the journal. That this is not always the case is the motivation for this editorial. There have been instances where the author list on a manuscript submitted to APESM has changed after submission. Often the change is not notified by the authors but is instead detected by the publishing staff. While it is possible to change the listed authors after the manuscript has been submitted, the change needs to be requested and explained.

If the request for change is made before the manuscript is sent to reviewers, for example when the APESM editor returns the manuscript to the authors for a required revision before the manuscript is accepted for review, then APESM does not consider the change to be a substantial one, and the change will usually be accepted without question. Prior to submitting a manuscript to a journal, the authors should be aware of the recommendations of the International Committee of Medical Journal Editors (ICMJE) that a listed author should meet the following four criteria. According to their recommendations, an author should have made a substantial contribution to the:

- conception or design of the work; or the acquisition, analysis, or interpretation of data for the work;

- drafting of the work or its critical revision for important intellectual content;

Martin Caon

Martin.caon@flinders.edu.au

1 School of Health Sciences, Flinders University, Adelaide, Australia
In addition all listed authors should provide:

- final approval of the version to be published;

- agreement to be accountable for all aspects of the work in ensuring that questions related to the accuracy or integrity of any part of the work are appropriately investigated and resolved.

Note that the use of the word "all" in the fourth criterion has caused some debate. The ICMJE go on to state: "Examples of activities that alone (without other contributions) do not qualify a contributor for authorship are: acquisition of funding; general supervision of a research group or general administrative support; and writing assistance, technical editing, language editing, and proofreading." [1].

\section{Who should be listed as an author?}

Springer (who produce this journal) have a simple and unprescriptive statement of authorship. They state: "Although there is no universal definition of what constitutes authorship it is generally believed that authors should be identified by the research group as having contributed sufficiently to the scientific work, who are accountable for their part of the work, and who critically reviewed and approved the final manuscript. Criteria: authoring, drafting, reviewing, approving." [2].

The person who drafts the manuscript and who presumably did a substantial part of the work should be listed and probably as first author. If this is a graduate student, then their supervisor(s) would be listed as well. If the work is supported by a financial grant, the scientists who were listed on the successful grant proposal would presumably do some of the work and would most likely be among 
Table 1 Average number of authors per oral presentation at EPSM conferences and for APESM articles

\begin{tabular}{lll}
\hline $\begin{array}{l}\text { Year of EPSM conference/year of } \\
\text { APESM Journal }\end{array}$ & $\begin{array}{l}\text { Average number of authors (\# of oral } \\
\text { presentations) }\end{array}$ & $\begin{array}{l}\text { Average number of } \\
\text { authors (\# of APESM } \\
\text { articles) }\end{array}$ \\
\hline 1997 & $2.6(118)$ & $2.5(34)$ \\
2001 & $3.1(88)$ & $2.4(21)$ \\
2004 & $3.1(100)$ & $3.3(27)$ \\
2007 & $3.7(114)$ & $3.9(26)$ \\
2010 & $3.9(137)$ & $3.5(32)$ \\
2013 & $4.8(161)$ & $4.3(39)$ \\
2016 & $5.2(168)$ & $4.5(84)$ \\
\hline
\end{tabular}

the authors. The scientist research assistant(s) who was recruited because of their scientific expertise, and did the work should be listed. Collaborators who were involved because they contributed their particular scientific expertise are also candidates for listing as co-authors.

All candidates for co-authorship should be invited to be authors and should read and criticise the draft manuscript. This is important so deserves repeating. Everyone should read and provide critical comments on the manuscript. In fact the person drafting the manuscript should specifically ask the authors who are involved because of their particular expertise, to provide comments on that part of the draft manuscript that relates to their particular expertise. It is expected that no-one who meets the criteria for authorship is omitted from the author list. Hence it is important that "ghost" authors are not omitted, that "guest" authors are not included and that authorship is not "gifted".

APESM is unconcerned about the order in which the authors are listed. The order is for the authors themselves to decide. It may be that the graduate student's name is first and that of the major supervisor is last. The authors may be listed in the sequence of the magnitude of their contribution. For a long list of authors, they may choose to be listed alphabetically. In the case of an article being a compilation of many sections produced by many authors, the authors may choose to be credited in the order in which their contribution appears-for example see [3].

\section{Changes in the list of authors}

The Springer guide [2] refers the confused editor to the COPE (Committee on Publication Ethics) flowcharts for advice on the resolution of authorship issues. Admittedly, each individual case will usually have its own nuances, but generally speaking APESM would handle them as broadly described below.

Of the manuscripts submitted to APESM, there have been instances where the list of authors has changed between revisions of the manuscript. This is usually allowed but needs to be requested and explained. If the change is for an additional author or for the deletion of an author, the request should be accompanied by a statement signed by all of the authors. If the request is for a change only in the sequence of already listed authors and arrives after the manuscript has been accepted, the request will not be granted without such a statement of agreement signed by all of the authors. If the requested change is for an additional author, or the removal of an author, and comes after the manuscript has been accepted for publication, the request will almost always be denied. Furthermore if a request for change arrives after the article has been published the request will certainly be denied. A possible exception to this might be when an author demands to be removed from the article author-list for a valid reason.

\section{The multiplying number of authors listed on scientific manuscripts}

It is clear that the number of authors listed on papers is increasing. I counted the number of authors listed on oral presentations given at a sample of EPSM conferences (sponsored by the ACPSEM who publish this journal) between 1997 and 2016. The average number of authors per paper is presented in Table 1. Keynote and invited speaker talks were excluded as they are almost always single authored. Poster presentations were excluded. Also presented in Table 1 are data for the average number of authors listed on articles published in APESM for the same time span (editorials, invited papers, recommendation and position papers were excluded). Both sets of data show an increase in the average number of listed authors with the article by Toshito et al. [4] holding the record with 21 authors.

The data in Table 1 resembles very closely the Thomson Reuters data on the average number of authors on published papers from all fields. Their average is reported as having risen from 2.5 authors in 1981 to 3.0 in 1991, 3.8 in 2001 and to about 5 in 2011 [5]. 
When one speculates on the reasons behind the inflation in the author list for conference talks and published articles several potential reasons suggest themselves:

Perhaps there are more Big Medical Physics projects in Australia now than in the past (for example the Australian MRI-Linac; the Monash synchrotron; large cancer trials). Perhaps more medical physics registrars are publishing their work in conjunction with their supervisors and this necessarily leads to multiple authors. Employers are reluctant to provide conference funding unless you are a presenter and so there may be an incentive to extend the author list. There is pressure from employing institutions to produce measurable research outcomes (publications) and this exerts pressure on scientists to seek co-authorship more avidly. Perhaps some people are being listed without satisfying the four ICMJE criteria for authorship. Can you think of any other reasons for the increase?

The increasing number of people that are appearing on the author list of published manuscripts suggests that the potential for authorship issues to arise has also increased. Hence the prophylactic advice on COPE's 2008 flowchart [6] is sound:

To prevent future problems:

1. Before publication, get authors to sign a statement that all listed authors meet authorship criteria and that no others meeting the criteria have been omitted
2. Publish details of each person's contribution to the research and publication.

\section{References}

1. ICMJE (2015) http://www.icmje.org/recommendations/browse/ roles-and-responsibilities/defining-the-role-of-authors-and-contributors.html. Accessed 27 Oct 2016

2. Springer (2015) Publishing Ethics for journals. A guide for Editors-in-Chief, Associate Editors, and Managing Editors http://static.springer.com/sgw/documents/1393202/application/pdf/Publication_Ethics_Guide_for_Editors_from Springer_27052013.pdf. Accessed 27 Oct 2016

3. Round WH, Jafari S, Kron T et al (2015) Brief histories of medical physics in Asia-Oceania. Australas Phys Eng Sci Med 38(3):381-398. doi:10.1007/s13246-015-0342-9

4. Toshito T, Omachi C, Kibe Y, Sugai H et al (2016) A proton therapy system in Nagoya Proton Therapy Center. Australas Phys Eng Sci Med 39(3):645-654

5. King, C (2013) Single-Author Papers: a waning share of output, but still providing the tools for progress http://sciencewatch.com/ articles/single-author-papers-waning-share-output-still-providing-tools-progress. Accessed 28 Oct 2016

6. COPE (2008) Flowcharts (available from http://www.publicationethics.org. or http://home.jeet.or.kr/Flowcharts.pdf) 